\title{
Estudos de usuários: quais as diferenças entre os conceitos comportamento informacional e práticas informacionais?
}

\author{
User studies: what are the differences between concepts informational behavior and in- \\ formational practices?
}

\author{
Flávia Virginia Melo Pinto \\ Doutoranda em Ciência da Informação \\ Universidade Federal de Minas Gerais \\ biblioflavia@gmail.com \\ Carlos Alberto Ávila Araújo \\ Doutor em Ciência da Informação \\ Universidade Federal de Minas Gerais \\ casalavila@yahoo.com
}

\begin{abstract}
Resumo
Abordamos as diferenças entre os conceitos comportamento informacional e práticas informacionais, suas diferenças de concepção e aplicação no subcampo Estudos de Usuários da Informação. Tais conceitos se tornaram guarda-chuva, abrigando diferentes concepções teórico-metodológicas. A metodologia utilizada foi exploratória, com levantamento bibliográfico e documental. Concluímos com apresentação de uma definição para Práticas Informacionais considerando as múltiplas determinações da vida em sociedade.
\end{abstract}

\section{Palavras-chave}

Comportamento Informacional. Estudos de usuários. Práticas informacionais.

\begin{abstract}
We address the differences between the concepts informational behavior and informational practices, their differences in conception and application in the Information User Studies subfield. Such concepts became umbrella, sheltering different theoretical-methodological conceptions. The methodology used was exploratory, with bibliographic and documentary survey. We conclude by presenting a definition for Informational Practices considering the multiple determinations of life in society.
\end{abstract}

\section{Keywords}

Information Behavior. User studies. Information Practices.

\section{INTRODUÇÃO}

O objetivo deste artigo é abordar as diferenças de concepção entre os conceitos construídos no subcampo de Estudos de Usuários da Informação: comportamento informacional e práticas informacionais. Entendemos que ambos os conceitos abarcam diferentes concepções teórico-metodológicas, não havendo definições unívocas, apontando para a complexidade que se tem tornado as abordagens neste subcampo. 
Adotamos a metodologia caracterizada como exploratória, com levantamento de literatura, a fim de obter materiais que abordem os conceitos apresentados para que possamos caracterizar as diferenças teórico-metodológicas entre eles. De acordo com Marconi e Lakatos (2006, p. 71), a pesquisa bibliográfica não pode ser entendida como "[...] mera repetição do que foi dito ou escrito sobre certo assunto, mas propicia o exame de um tema sob novo enfoque ou abordagem, chegando a conclusões inovadoras.".

Estudos de usuários se consolidaram como disciplina nas graduações de Arquivologia e Biblioteconomia, e como um subcampo de pesquisa da Ciência da Informação. Abrangem desde levantamentos de uso de fontes de informação em bibliotecas e arquivos até pesquisas mais complexas para desenvolvimento de sistemas ou ampliação do escopo conceitual em busca do entendimento sobre os processos de demanda, necessidade, busca, uso, produção e disseminação de informações pelas pessoas ligadas ou não às instituições. Nesse artigo, pretendemos apresentar revisão bibliográfica dos estudos sobre comportamento informacional e práticas informacionais, objetivando apontar suas aproximações e diferenças teórico-metodológicas.

A literatura indica duas origens dos estudos de usuários de bibliotecas e da informação. Os estudos sobre uso das bibliotecas da década de 1930, na Universidade de Chicago, Estados Unidos da América, e a publicação na Conferência de Informação Científica da Royal Society, em 1948, de trabalhos sobre necessidades de informação de pesquisadores e outros profissionais (FIGUEIREDO, 1994).

A chegada de grande contingente de imigrantes na cidade de Chicago, no início do século XX, mobilizou os serviços públicos para a socialização e adaptação das pessoas aos hábitos locais. Os estudos realizados na Universidade de Chicago objetivavam preparar as bibliotecas para fornecerem materiais informativos sobre os hábitos e a cultura local para facilitar a socialização dos estrangeiros (FIGUEIREDO, 1994).

O segundo marco se diferenciou dos primeiros estudos por se voltar para as necessidades informacionais de grupos determinados, "[...] a ênfase foi em tentar-se descobrir o uso da informação pelos cientistas e engenheiros, por serem as áreas nas quais os problemas eram mais sentidos e os sistemas em uso mais se ressentiam das inadequações." (FIGUEIREDO, 1994, p. 9). Contudo, o termo estudos de usuários apareceu, pela primeira vez, em 1960 substituindo o conceito levantamento bibliográfico.

Os estudos pioneiros se ocupavam com a administração de bibliotecas como o trabalho de Wight (1937) que determinou os passos a serem seguidos num levantamento de informações para o estabelecimento de serviços bibliotecários. O autor apontou a necessidade de definição dos propósitos e limites do estudo; preparação de um esboço da organização do relatório final; determinação dos tipos de dados e dos métodos de coleta; preparação das tabelas, formulários e impressos para coleta e tabulação dos dados; coleta de dados; tabulação e análise; preparação dos relatórios; revisão, crítica e preparação final do relatório. Nos estudos seguintes, surgiu a preocupação proposta por Mc Diarmid (1940) em aproximar os indivíduos não usuários aos serviços da biblioteca; a demonstração das diferenças entre estudos de comunidades e estudos administrativos na abordagem de McMillen (1944); e o estudo de Martin (1944) sobre a relação entre as características e condições sociais dos indivíduos com seus hábitos de leitura (FIGUEIREDO, 1994).

Na década de 1960, conforme destacam Baptista e Cunha (2007, p. 171), os estudos "[...] se preocupavam em identificar notadamente a frequência de uso de determinado material e outros comportamentos de forma puramente quantitativa e não detalhavam os diversos tipos de comportamentos informacionais." O fato marcante desse período foi o 
início da publicação no Annual Review of Information Science and Tecnology (ARIST) de um capítulo sobre necessidades e usos da informação.

Até a década de 1970, as preocupações se limitavam a avaliação de bibliotecas e a descrição dos fluxos de informação. Araújo (2008) afirma que esses estudos tinham o objetivo de estabelecer modelos de comportamentos de busca de informação como, por exemplo, o "princípio do menor esforço". A maioria desses estudos utilizou questionário, normalmente composto por perguntas com o objetivo de coletar dados para quantificar hábitos de busca e uso da informação e verificar a frequência de acesso aos sistemas de informação e graus de satisfação dos grupos pesquisados.

A preocupação em se identificar como os usuários obtinham e usavam a informação surge mais tarde, "[...] na década de 70 a preocupação maior passa a ser o usuário e a satisfação de suas necessidades de informação [...]." (FIGUEIREDO, 1994, p. 2). Esses trabalhos possibilitaram o conhecimento das várias fontes que os cientistas observados consultavam antes de dirigirem-se à biblioteca, além da identificação de critérios usados pelos usuários no momento da busca da informação, como sua forma, o tempo gasto e o lugar onde ela esteja disponível, etc. (FIGUEIREDO, 1994).

Até esse momento os pesquisadores tentavam responder a questão: para quem era a informação? E o usuário era apenas o informante e não objeto de estudo, considerado de maneira passiva, tendo que se adaptar aos mecanismos dos serviços de informação (FERREIRA, 1996). As pesquisas sobre usuários da informação, até então, ficaram conhecidas como abordagem ou paradigma tradicional ou a fase de estudos quantitativos.

Gasque e Costa (2010, p. 27) descreveram sete características predominantes das pesquisas realizadas sob o paradigma tradicional, cuja orientação metodológica era baseada no positivismo e empirismo. A primeira é a objetividade que considera a informação como "algo com significado constante, correspondendo de forma absoluta à realidade". A segunda característica seria o mecanicismo dos estudos que focavam o funcionamento dos sistemas, desprezando os atributos dos usuários o que levaria à terceira característica que é a passividade dos usuários entendidos como "receptáculos passivos de informação objetiva". A tentativa de prever o "comportamento dos usuários por meio de estatísticas e modelos que poderiam ser aplicados em várias situações" seria a quarta característica. O foco na interação entre usuários-sistema; a concepção de observação do comportamento externo do usuário, tido como objetivo e captável pela experiência do pesquisador; e a crença de que as pesquisas produziriam "observações sistemáticas e padrões de comportamento para os sistemas de informação" seriam as três últimas marcas dos estudos tradicionais.

Essas concepções foram verificadas, sobretudo nos estudos produzidos nos Estados Unidos da América, país que se estabeleceu como hegemônico após a Segunda Guerra Mundial e travava uma corrida espacial e bélica com a então União Soviética. 0 desenvolvimento industrial e técnico-científico produzia e demandava grande quantidade de informações que deveriam ser controladas e compartilhadas entre os grupos certos, de maneira mais dinâmica.

\section{O INDIVÍDUO COMO O CENTRO}

Com o tempo, os pesquisadores da área perceberam os limites teóricometodológicos da abordagem tradicional. Os pesquisadores começaram a problematizar como os indivíduos lidavam interiormente com a informação ou a falta dela. Precisavam entender melhor os aspectos cognitivos em torno da demanda, necessidade, busca e uso da 
informação. Assim, nos anos de 1980, surgiram as primeiras contribuições da chamada abordagem alternativa, paradigma moderno ou a fase de estudos qualitativos que, de acordo com Baptista e Cunha (2007, p. 173),

[...] focaliza a sua atenção nas causas das reações dos usuários da informação e na resolução do problema informacional, ela tende a aplicar um enfoque mais holístico do que o método quantitativo. Além disso, ela dá mais atenção aos aspectos subjetivos da experiência e do comportamento humano.

Sob a abordagem alternativa, tentou-se responder a questão: informação para fazer o quê? Para Ferreira (1996, p. 220):

[...] as pesquisas estão centradas no indivíduo, partindo de uma perspectiva cognitiva, buscando interpretar necessidades de informação tanto intelectuais como sociológicas. Análises estão sendo feitas sobre as características únicas de cada usuário buscando chegar às cognições comuns à maioria deles.

Esses estudos focavam o usuário e sua relação com o sistema de informação. Os sistemas de informação deveriam ser flexíveis o bastante para possibilitar ao usuário adaptar a busca pela informação à sua necessidade corrente. Sob esse paradigma foram desenvolvidos os modelos "valor agregado" de Robert Taylor (1986), "estado anômalo de conhecimento" de Belkin (1980), "Sense-Making" ou "construção de sentido" de Brenda Dervin (1998), "comportamento informacional" de Thomas Wilson (1981, 2000), entre outros. No Quadro 1, retomamos os resumos das abordagens centradas no usuários de uma revisão bibliográfica feita por Costa, Silva e Ramalho (2009).

Quadro 1 - Abordagens de Estudos de Usuários centradas nos indivíduos

(continua)

\begin{tabular}{|c|c|}
\hline Autores & Resumo da abordagem \\
\hline $\begin{array}{l}\text { Dervin } \\
\text { (1998) }\end{array}$ & $\begin{array}{l}\text { Conjunto de premissas conceituais e teóricas para analisar como pessoas constroem sentido } \\
\text { em seus mundos e como usam a informação e outros recursos nesse processo. Procura lacu- } \\
\text { nas cognitivas e de sentido expressas em forma de questões que podem ser codificadas e } \\
\text { generalizadas a partir de dados diretamente úteis para a prática da comunicação e informa- } \\
\text { ção. }\end{array}$ \\
\hline $\begin{array}{l}\text { Wilson } \\
(1981,2000)\end{array}$ & $\begin{array}{l}\text { Modelo baseado nas seguintes proposições: as necessidades de informação têm sua gênese } \\
\text { nas necessidades básicas do sujeito, (fisiológicas, cognitivas e afetivas), logo não é uma neces- } \\
\text { sidade primária, mas sim, secundária; e, diante da busca de informação para satisfazer sua } \\
\text { necessidade, o sujeito pode deparar-se com barreiras individuais, pessoais, inter-pessoais e } \\
\text { ambientais. }\end{array}$ \\
\hline Belkin (1980) & $\begin{array}{l}\text { A abordagem do Estado Anômalo do Conhecimento (Anomalous States of knowledge) focaliza } \\
\text { pessoas em situações problemáticas, em visões da situação como incompletas ou limitadas de } \\
\text { alguma forma. Usuários são vistos como tendo um estado de conhecimento anômalo, no qual } \\
\text { é difícil falar ou mesmo reconhecer o que está errado, e enfrentam lacunas, faltas, incertezas } \\
\text { e incoerências, sendo incapazes de especificar o que é necessário para resolver a anomalia. }\end{array}$ \\
\hline $\begin{array}{l}\text { Taylor } \\
\text { (1986) }\end{array}$ & $\begin{array}{l}\text { A abordagem do Valor Agregado (User-values ou Value-added) focaliza a percepção da utili- } \\
\text { dade e valor que o usuário traz para o sistema. Pretende fazer do problema do usuário o foco } \\
\text { central, identificando diferentes classes de problemas e ligando-os aos diferentes traços que } \\
\text { os usuários estão dispostos a valorizar quando enfrentam problemas. É um trabalho de orien- } \\
\text { tação cognitiva em processamento da informação. }\end{array}$ \\
\hline
\end{tabular}

Fonte: Adaptado de Costa, Silva e Ramalho (2009, p. 08-09). 
Quadro 1 - Abordagens de Estudos de Usuários centradas nos indivíduos

\begin{tabular}{|l|l|}
\hline \multicolumn{1}{|c|}{ Autores } & \multicolumn{1}{c|}{ (continuação) } \\
\hline $\begin{array}{l}\text { Ellis (1989) } \\
\text { Hall (1993) }\end{array}$ & $\begin{array}{l}\text { Modelo de comportamento de busca de informação que parte do pressuposto de que o pro- } \\
\text { cesso de busca se dá por meio de aspectos cognitivos, constituído por etapas que não aconte- } \\
\text { cem de forma sequencial, características gerais que não são vistas como etapas de um proces- } \\
\text { so. Inicialmente se baseia em seis categorias de análise: Iniciar, Encadear, Vasculhar, Diferen- } \\
\text { ciar, Monitorar, Extrair. Posteriormente, esse modelo foi aperfeiçoado pelo próprio Ellis em } \\
\text { conjunto com Cox e Hall (1993) que acrescentaram mais duas categorias ao modelo original } \\
\text { que são: Verificar e Finalizar. }\end{array}$ \\
\hline $\begin{array}{l}\text { Kuhlthau } \\
\text { (1994) }\end{array}$ & $\begin{array}{l}\text { Modelo denominado de Information Search Process se baseia no conceito de estado anômalo } \\
\text { do conhecimento de Belkin (1982), potencializado pela Teoria Construtivista em que a apren- } \\
\text { dizagem de um novo conhecimento se realiza por uma construção individual e ativa e não } \\
\text { pela transmissão. O processo se desenvolve em seis estágios: Iniciação. Seleção, Exploração, } \\
\text { Formulação, Coleta e Apresentação. Cada estágio se caracteriza pelo comportamento do } \\
\text { usuário em três campos de experiência: o emocional, o cognitivo e o físico. }\end{array}$ \\
\hline Choo (2003) & $\begin{array}{l}\text { Modelo que ressalta três propriedades da busca e do uso da informação: a) o uso da informa- } \\
\text { ção é estabelecido a partir do significado que o indivíduo lhe impõe, à luz de suas estruturas } \\
\text { emocionais e cognitivas. b) o uso da informação é situacional. O indivíduo faz parte de um } \\
\text { meio, profissional ou social, que afeta, diretamente, suas escolhas para o uso da informação. } \\
\text { c) o uso da informação é dinâmico, interagindo com os elementos cognitivos, emocionais e } \\
\text { situacionais do ambiente, que impulsionam o processo de busca da informação, modificando } \\
\text { a percepção do indivíduo em relação ao papel de informação e os critérios pelos quais a in- } \\
\text { formação é julgada sob um dado assunto. A busca se caracteriza por um processo implemen- } \\
\text { tado pelo indivíduo para modificar o estágio anterior. }\end{array}$ \\
\hline
\end{tabular}

Fonte: Adaptado de Costa, Silva e Ramalho (2009, p. 08-09).

Gasque e Costa (2010, p. 27) identificaram as seguintes características nessa abordagem centrada nos indivíduos: "reconhecimento da subjetividade resultante de uma realidade que não transmite significado constante"; a adoção de certa perspectiva construtivista que compreende o conhecimento como algo "construído pelas relações humanas" por meio da linguagem que se desenvolve numa comunidade e num contexto, sendo os usuários pessoas ativas com objetivos e preferências, cujo comportamento informacional irá variar conforme a situação, o sistema passa a ser considerado um dos elementos de contexto social amplo; o centro é o aspecto cognitivista e a individualidade. $\mathrm{O}$ novo momento exige novas orientações metodológicas que privilegiam os métodos qualitativos de coleta e análise de dados. E o termo comportamento informacional passa a ser recorrente nas pesquisas cognitivistas.

O cognitivismo considerava que, em alguns momentos, as pessoas poderiam ter uma lacuna resultante da falta de informações para a resolução de algum problema como se fosse possível, de repente, um determinado vazio cognitivo. O foco seria captar esse comportamento informacional para esclarecer como que o indivíduo age quando percebe essa lacuna. A abordagem construtivista sense making ou construção de sentido de Brenda Dervin (1998) é a que melhor ilustra essa relação do sujeito com a informação atomizada. Para a pesquisadora, o caminho do conhecimento é uma estrada por onde o sujeito segue, encontrando constantemente lacunas, necessitando construir pontes para ultrapassá-las. As lacunas seriam vazios cognitivos e as pontes seriam construídas pelas informações necessárias ao preenchimento desses vazios, resultando na construção de novos conhecimentos. 
No início da década de 1980, Thomas Wilson (1981) se dedicou à elaboração de modelo de comportamento informacional a partir da observação e descrição de características dos indivíduos com sistemas de informação, objetivando sua otimização. Quase 20 anos depois, esse autor aprofundou a descrição de seu modelo, apresentando quatro definições sobre comportamento das pessoas com relação às informações. Information behavior ou comportamento informacional, a mais usada, abrange a totalidade das relações humanas com fontes e canais de informação, procuras ativas ou recebimento passivo, uso da informação. Information seeking behavior ou comportamento de busca informacional está relacionado à procura intencional para satisfazer uma necessidade. Information searching behavior ou comportamento de pesquisa informacional envolve todos os atos com um sistema de informação seja no acesso à primeira página apresentada ou no uso de estratégias de busca mais complexas, envolvendo a avaliação e combinação das informações recuperadas. Information use behavior ou comportamento no uso da informação consiste nos atos físicos e mentais envolvidos na incorporação da informação encontrada. Os atos físicos seriam a identificação num texto dos trechos mais relevantes, por exemplo, e os atos mentais a comparação com os conhecimentos que pessoa já possui (WILSON, 2000).

O autor ampliou o escopo do conceito de comportamento informacional, considerando várias atitudes em relação à necessidade, à busca e ao uso de informações, ao diferenciar essas dimensões em outros conceitos mais específicos. Porém, a concepção ainda é reducionista ao focar em atitudes individuais como se não fossem produto de relações humanas e sociais, negligenciando fatores da interação dos indivíduos em sociedade, se relacionando em determinados contextos histórico-sociais, envolvendo conflitos decorrentes das posições sociais ocupadas pelos indivíduos.

As "dimensões situacionais" de necessidade, busca e uso da informação foram abordadas por Taylor (1986) que considera o ambiente estanque, limitado a um determinado contexto. Sua teoria é que cada ambiente apresentará um tipo de problema e que os grupos partilham os pressupostos sobre a natureza de seu trabalho e o papel que as informações podem desempenhar nele. Não observamos nas explicações de Taylor atenção dada às disputas, ao controle da informação que pode ser exercido por determinado interesse de um grupo ou de uma pessoa ou a posição que a organização ocupa na estrutura social, qual é o papel dela e o que isso pode significar na geração e no uso de informações no seu cotidiano.

Ao analisar os artigos sobre as pesquisas envolvendo o comportamento informacional, Savolainen (2007) verificou que não houve debates sobre a necessidade e legitimidade desse conceito que acabou acolhendo diferentes definições ou tipos de comportamento informacional sem a caracterização do próprio conceito.

Para Savolainen (2007), Wilson (2000) foi o autor que mais se dedicou a tentar consolidar as definições sobre comportamento informacional que acabou se tornando um conceito guarda-chuva na medida em que emerge de diferentes discursos que sugerem modelos de como interpretar os fenômenos de busca de informação, entre outros. A inquietação levantada por Savolainen (2007) era se pesquisadores estavam se atentando às implicações discursivas dos conceitos de comportamento informacional e de práticas informacionais. Para responder a essa questão, ele analisou os capítulos do ARIST desde 1966, levantando 150 fontes indexadas com os conceitos information behavior e information practice (prática informacional, sobre o qual abordaremos adiante), dentre as quais, foram escolhidas 100 para uma revisão. Savolainen (2007) estava interessado na análise discursiva 
dos artigos, entendendo que os discursos são construídos a partir da seleção, organização e combinação de conceitos, num contexto de disputa pelo poder e ocultamento das ideologias. Não há neutralidade na escolha de um ou outro conceito, que carrega na sua aplicação concepções teórico-metodológicas específicas.

Apesar do consenso na adoção de uma perspectiva metodológica behaviorista, Savolainen (2007) verificou um processo de luta discursiva em torno do conceito de comportamento informacional, muitas vezes, naturalizando-o, ou seja, partindo do pressuposto que ele sempre existiu como parte da subjetividade humana e não como um conceito desenvolvido a partir do ponto de vista do pesquisador. É um conceito usado como autoevidente, como se houvesse consenso na área em torno da sua definição e características. Assim, esse conceito se tornou uma espécie de guarda-chuva por abrigar diferentes abordagens teóricas.

Os trabalhos que objetivavam analisar a relação das pessoas com informações passaram a usar a denominação comportamento informacional, independente da concepção teórico-metodológica usada e o próprio conceito passou a ser naturalizado, como se sempre tivesse existido, portanto, passível de ser transposto da realidade para um modelo que poderia ser aplicado a diferentes contextos. Assim, a busca pela construção de modelos de comportamento informacional que pudessem ajudar a prever as reações humanas e auxiliar no desenvolvimento e na otimização de sistemas de informação.

\section{ABORDAGEM SOCIAL E O CONCEITO DE PRÁTICAS INFORMACIONAIS}

A ênfase no indivíduo, muitas vezes, considerado como um ser com lacunas a serem preenchidas com informações também se mostrou insuficiente para compreender os fenômenos de demanda, necessidade, busca, uso e disseminação de informações. Um pensamento simplista que desconsidera a complexidade da mente humana. $O$ ato de conhecimento é tomado como um processamento apenas de somatório de dados. Alguns pesquisadores passaram a considerar os aspectos das relações entre as pessoas em seus respectivos contextos para estudarem os fenômenos informacionais. Além disso, foram ultrapassados os limites dos grupos profissionais e acadêmicos, e a vida cotidiana passa a ser considerada. Esses são elementos da abordagem social dos estudos de usuários.

Case (2002) realizou uma profunda revisão bibliográfica sobre as abordagens em comportamento informacional, apontando os paradoxos da existência de diversas concepções teórico-metodológicas que proporcionam conduções diferenciadas na observação desse fenômeno. Se por um lado passou a existir uma diversidade maior de pessoas como sujeitos das pesquisas, resultando na descrição de variados comportamentos, por outro, há também maior fragmentação de exemplos de comportamento informacional. Ele questiona se a área não está passando por outro extremo de se estudar cada vez amostras menores em contraposição aos grandes grupos que eram estudados inicialmente como os engenheiros. $O$ autor considera ainda que é difícil resistir à conclusão de que a literatura sobre comportamento informacional é um tanto modesta. Certos temas e fontes são citados por um estudo levantado em estudos posteriores, mas sem necessariamente levar a um avanço da teoria ou a um acúmulo de descobertas comparáveis.

Consideramos importantes as oito lições apresentadas por Case (2002, p. 289-290) a partir da análise dos modelos de comportamento informacional para refletirmos sobre que tipo de olhar lançaremos para os estudos da relação que as pessoas estabelecem com as informações. A começar, Case (2002) afirma que fontes formais e pesquisas racionalizadas 
refletem apenas um lado do comportamento informacional humano. As pesquisas demonstram que a maioria das pessoas procura sanar suas dúvidas com pessoas mais próximas, familiares, colegas de trabalho ou pelos meios de comunicação de massa. Ter acesso a muitas informações nem sempre é o melhor e o contexto é central para a transferência de informações.

Às vezes, fornecer pacotes generalizados de informação não ajuda: as pessoas não sentem necessidades básicas de informações como sentem de comer, se abrigar ou se vestir. Frequentemente, elas precisam de informações personalizadas para resolver seus problemas e uma padronização de respostas de um sistema de informação talvez não satisfazerá essas necessidades. Além disso, às vezes, sistemas de informação formais não atenderão às demandas imprevisíveis de informação de maneira satisfatória. (CASE, 2002).

A busca por informação é um processo dinâmico: uma questão pode ser satisfeita rapidamente, mas a natureza da pergunta pode se modificar durante vários momentos da pesquisa ou a resolução de um problema pode gerar uma nova questão. Mas, a dificuldade de se estudar um cenário tão instável leva a uma tendência a se considerar um episódio de busca de informações como algo bastante simples, linear e completo. $\mathrm{O}$ script usual assume que surge uma necessidade, uma pessoa realiza uma pesquisa de uma única fonte em um canal específico e encontra uma resposta. Não é direto, nem tipicamente completo; é mais como uma série de interrupções, pontuadas por outras interrupções. De acordo com essa percepção, modelos mais recentes de busca de informações enfatizaram a natureza dinâmica e interativa das necessidades e pesquisas. A busca de informações nem sempre é sobre problema ou uma situação problemática: há necessidade de criatividade do pesquisador para entender de fato o processo de busca de informações frente ao fato de que as pesquisas não conseguem explicar, por exemplo, por que as pessoas agem da mesma maneira ao buscar informações. (CASE, 2002).

Por fim, Case (2002) foca na abordagem de Brenda Dervin, afirmando que comportamento informacional não é sempre sobre construção de sentido: apesar do foco na construção de sentidos ao invés do uso, estudos sobre busca de informações ainda é o estudo sobre recursos de informação. A abordagem sense-making é valiosa, mas não captura todos os aspectos do comportamento informacional. Para certos problemas, continua sendo útil pensar em termos antigos, como preferência de fontes e segmentação de público-alvo, principalmente, tendo em vista a larga utilização das fontes virtuais de informação e das redes sociais.

Em busca de uma concepção que amplie a visão de comportamento informacional, Costa e Ramalho (2019, p.134) apresentaram uma revisão bibliográfica de trabalhos que passaram a utilizar o termo comportamento infocomunicacional que, na contemporaneidade, consideram "[...] a articulação das práticas informacionais e comunicacionais como relacionamento, socialização, liderança, poder, estruturas, processos, aprendizagem, inteligência, motivação, satisfação, tomada de decisão, dentre outros.".

As autoras apontaram a importância de contribuições particulares ou interdisciplinares das áreas de Ciência da Informação, Administração, Comunicação Social, Psicologia, Psicologia Social, Sociologia, Antropologia, Ciência Política, História, Ciências da Computação, Engenharia, Filosofia e Educação. Cada área tem desenvolvido estudos que envolvem diversos aspectos dos fenômenos informacionais entre grupos sociais, envolvendo ou não as tecnologias de informação e comunicação. Isso porque tais fenômenos estão se tornando cada vez mais complexos afetando e sendo afetados por diversos aspectos desde os econômicos até os culturais, identitários e simbólicos. 
O financiamento/investimento econômico, portanto, em pesquisas que possam revelar o comportamento infocomunicacional de acordo com interesses organizacionais, sobre segmentos de mercado, serviços utilizados, etc. na incrementação de produtos e sua comercialização, principalmente através das TIC, é cada vez mais comum e constante. Dessa forma, esses estudos têm se voltado desde ações sociais, comércio e prestação de serviços tradicionais, até e-commerce, e-government, e-business. A prospecção/implementação/venda de serviços e novos produtos como sites, jogos de computador, software, TV digital e, mais recentemente, a interação móvel. (COSTA; RAMALHO, 2019, p. 142).

Se por um lado temos produção e fornecimento de mercadorias tangíveis ou não cada vez mais informatizadas, por outro convivemos com o paradoxo da existência de uma geração de nativos digitais, considerada mais evoluída e que domina facilmente as novas tecnologias e uma massa de pessoas excluídas do acesso às tecnologias de informação e comunicação. Nossa sociedade ainda é marcada por profundas desigualdades sociais demonstradas pelas estatísticas oficiais. O censo do ano de 2010 do Instituto Brasileiro de Geografia e Estatística (IBGE) identificou que no Brasil há mais de 16 milhões de pessoas vivendo com renda per capta mensal de até $\mathrm{R} \$ 70,00$ (setenta reais), aquém da linha de extrema pobreza conforme acepção do governo brasileiro (IBGE, 2010). O Banco Mundial (THE WORLD BANK, 2018) apontou que no ano de 2015 havia 1,9 bilhão de pessoas em extrema pobreza no mundo, vivendo com US\$ 3,20 por dia e cerca de metade da população, 3,4 biIhões de pessoas vivendo com menos de US\$ 5,50 diariamente. Costa e Ramalho (2019) apontaram essas contradições e como elas podem impactar na produção e no acesso a informações, demonstrando a complexidade de se explicar o comportamento infocomunicacional, daí a necessidade da interlocução de diversas áreas do conhecimento.

Nesse contexto, Costa e Ramalho (2019, p.150-152) elencaram alguns modelos mais abrangentes que, mesmo não utilizando o termo comportamento infocomunicacional, possuem perspectivas metodológicas mais amplas que as usadas na perspectiva de comportamento informacional. Podemos citar: a Abordagem da Cognição Situada de Clancey (1997); - Modelo de Análise Contrastiva elaborado por Fróes Burnham (2002) para analisar processos de tradução do conhecimento científico objetivando a sua democratização; o Modelo de Necessidades Informacionais (NEIN) de Calva González (2004); o modelo, elaborado pelas próprias autoras e denominado de Estudos Híbridos de Uso da Informação, que parte do confronto teórico-metodológico de referências da Engenharia da Usabilidade, Ciência da Computação e Ciência da Informação, numa perspectiva aberta (COSTA; RAMALHO, 2010a, 2010b); o Modelo Semântico para Estruturação da Informação (MSEI) de Miranda (2010), elaborado a partir das experiências individuais com os sistemas de recuperação da informação; a Abordagem Interacionista de Estudo de Usuários da Informação de Araújo (2010) que busca compreender os sentidos das ações dos sujeitos em relação aos fenômenos informacionais; o Modelo Integrativo de Comportamento Informacional elaborado por Mafra Pereira (2013); o Modelo de Comportamento Infocomunicacional em Contextos de Redes Sociais Online (RSO) de Silva e Silva (2012) e a Abordagem Clínica da Informação, metodologia empregada para a investigação do comportamento informacional no processo de tomada de decisão de líderes em organizações de Paula (2013).

Ressalta-se, porém, que o termo modelo não se refere às receitas estáticas a seguir, mas a caminhos teórico-metodológicos desenvolvidos por lastros sólidos epistemológicos, porém, ao mesmo tempo, flexíveis ao seu uso ou replicação até a sua evolução, como condutores de experiências exitosas em seus campos e aplicações. (COSTA; RAMALHO, 2019, p. 149). 
Nosso foco, porém, se deterá sobre autores que trabalharam com o conceito de práticas informacionais em contraposição ao conceito de comportamento informacional. Nesse sentido, Savolainen (1995) desenvolveu o conceito Everyday Life Information Seeking (ELIS) para relacionar aspectos socioculturais da formação dos indivíduos no processo de busca e uso das informações no cotidiano.

O conceito de ELIS refere-se à aquisição de vários elementos informacionais (cognitivos e expressivos) que as pessoas empregam para se orientarem no cotidiano ou para resolver problemas não diretamente ligados ao desempenho associado a diversas áreas do cotidiano, por exemplo: consumo e cuidados de saúde. (SAVOLAINEN, 1995, p. 266-267, tradução nossa).

Em 1996, aconteceu a conferência Information Seeking in Context e em 1999 a American Society for Information Science criou o grupo de pesquisa Information Needs, Seeking and Use. Os pesquisadores buscavam nas Ciências Sociais teorias que ajudassem a responder as questões em torno da relação das pessoas com os fenômenos informacionais. Havia uma preocupação em se ampliar o arcabouço teórico-metodológico para além do behaviorismo que era uma concepção limitadora ao se concentrar somente nos aspectos individuais e que não conseguia responder sobre as influências do grupo e do contexto onde o indivíduo estava inserido.

Podemos retomar o trabalho de Chatman (1999) que, ao observar as ações de indivíduos em situação de privação de liberdade, elaborou sua theory of life in the round partindo do pressuposto de que os grupos sociais criam sentidos sobre o que os rodeia, orientando suas ações, inclusive, com relação ao ato de se informar, de considerar a necessidade ou pertinência de determinada informação. Assim, ambientes como o presídio exigiriam dos indivíduos condutas específicas já esperadas por todos. Chatman (1999) relaciona essas condutas com as ações de busca de informações que garantam a sobrevivência dos indivíduos naquelas circunstâncias e naquele contexto. Para elaborar sua teoria, a autora recorreu à configuração do presídio, suas rotinas e constituição de grupos de acordo com seus interesses. Ao chegar à prisão, a pessoa deveria se apropriar rapidamente desses elementos como garantia da própria segurança e sobrevivência.

Pamela Mckenzie (2003) considerou as ações de busca da informação em qualquer contexto, em ações cotidianas que possibilitam, inclusive, que as pessoas acessem fontes de informação fortuitamente, sem estarem procurando por elas (o que autora chamou de serendipity). A autora elaborou um modelo bidimensional de práticas informacionais ao estudar as maneiras como um grupo de mulheres grávidas de gêmeos lida com as fontes de informação e com a própria informação durante a gravidez, a partir de seus relatos.

Identificaram-se quatro maneiras de busca que podem se realizar em duas etapas: fazendo conexão com a fonte identificada e/ou interagindo com essa fonte. Assim, foram descritas as seguintes práticas informacionais: fazendo conexões por meio da busca ativa de informações como, por exemplo, ligar para o médico para sanar alguma dúvida com relação à gestação. Fazendo conexões através da varredura ativa como, por exemplo, folhear um livro sobre gravidez numa biblioteca ou livraria sabendo identificar uma informação com relação à gravidez de gêmeos. Fazendo conexões por meio de monitoramento não direcionado, que seriam atividades regulares como ler um jornal ou assistir um noticiário diariamente. Fazendo conexões por procuração, quando um amigo ou familiar da mulher grávida resolve comprar um livro que encontrou casualmente e que trata do assunto ou quando ficam atentos a qualquer informação sobre gravidez de gêmeos para repassarem 
para a gestante. As características específicas das pessoas em determinados contextos também podem interferir nas práticas informacionais. Por exemplo, a barriga visível da gestante pode chamar atenção de outras pessoas cujas falas podem induzir a mulher a buscar informações.

Percebemos que o estudo de Mckenzie (2003) teve uma abordagem bem ampla, considerando diversos contextos e fontes de informação, incluindo ações da vida cotidiana e influências de vários sujeitos em diversas situações. Uma visão que rompe com a ideia de que a interação das pessoas com a informação deva ser estudada somente num contexto de serviço de informação ou de interação com um sistema ou a transferência de informações de pessoas experts em determinado assunto. Uma abordagem bem mais próxima da realidade das pessoas. Mas, a concepção metodológica ainda se restringe à elaboração de um modelo, uma forma de enquadrar a realidade, que é dinâmica e instável, a uma idealização feita pela pesquisadora.

Alison Yeoman (2010) repete o experimento anterior com 35 mulheres inglesas em menopausa, com o objetivo de atestar a flexibilidade de aplicação do modelo proposto por Mckenzie. Como conclusão, a autora identificou uma falha no modelo que não englobou a dimensão do uso da informação, quando o próprio sujeito pesquisado se torna uma fonte de informação. Novamente, a preocupação da pesquisadora era a replicação de um modelo, verificando sua adequação para diferentes públicos e contextos.

Apesar dos avanços teórico-metodológicos dessas pesquisas que passaram a considerar o ser humano na perspectiva das suas interações com o mundo, seus autores se mantiveram preocupados com a descrição de modelos de comportamentos informacionais mesmo considerando os aspectos culturais e contextuais dos sujeitos. Savolainen (1995), por exemplo, cria seus conceitos a partir da teoria social de Bourdieu sobre a constituição do Habitus nos e pelos sujeitos. No entanto, o autor se limita às relações contextuais dos sujeitos, diferente de Bourdieu (1983) que considerou o aspecto histórico da sociedade, as classes sociais, o conflito, a questão da diferença entre os grupos sociais que acaba se tornando em distinção, na elaboração da sua teoria. Assim, mesmo avançando em relação às perspectivas postas para os estudos de usuários, Savolainen mantém uma visão restrita dos sujeitos no exercício das práticas informacionais. Mckenzie (2003) e Yeoman (2010) se limitaram a construção de modelos de práticas informacionais desconsiderando também os aspectos que permeiam as relações sociais (entre as classes) e as relações privadas que também sofrem influências do arranjo da sociedade capitalista de produção.

Courtright (2007) fez uma revisão sobre como a categoria contexto passou a ser adotada nos estudos de comportamento informacional e levantou a existência de quatro concepções. Contexto no sentido de contêiner, o conjunto de elementos objetivos e observáveis em torno do indivíduo; contexto como construção de significados ou as maneiras como as pessoas percebem as influências; contexto também pode ser entendido como a construção das informações pelos indivíduos nas interações sociais. Por último, o contexto relacional que é resultante da percepção do pesquisador sobre o ponto de vista do indivíduo.

Percebemos que o contexto aparece espontaneamente, é algo localizado como o local de trabalho ou é construído por meio dos significados individuais. A historicidade, a localização no tempo e no espaço, o pertencimento de classe e o conflito são negligenciados nessa abordagem.

Os trabalhos citados desenvolveram teorias a partir do conceito de práticas informacionais, mas, como aponta Savolainen (2007), também há ausência de reflexão 
teórica e consequente pormenorização das suas características. Da mesma maneira que aconteceu com comportamento informacional, o conceito de prática passou a ser usado sem reflexão, dando nome às pesquisas que abordam os fatores sociais ou contextuais mesmo que sob diferentes perspectivas.

Entre os pesquisadores brasileiros, a adoção do conceito de práticas informacionais é ainda mais recente, apesar de Regina Marteleto (1994) ter usado essa expressão no título de um artigo que se propôs a realizar uma leitura histórico-social da construção da categoria informação como um problema prático-social e científico. A autora sintetizou assim a categoria informação no contexto contemporâneo:

No processo de dinâmica cultural, alimentado pelas práticas sociais em geral, informação se refere a uma forma moderna de veiculação e expressão de visões de mundo diferentes, porque elaboradas a partir de experiências de vida diversas e contraditórias. Por isso, deve ser considerada no plano das ações e representações dos sujeitos em suas práticas sociais históricas e concretas, enquanto um elemento que permeia cada uma dessas práticas. Num sentido ainda mais 'moderno', a informação é ela também uma prática, num contexto sócio-cultural de produção de discursos, representações e valores que informam cada existência, fornecendo a cada sujeito um modelo de competência (cognitiva, discursiva, comunicacional) para dirigir suas vidas, para se relacionar com os outros, com a sociedade (MARTELETO, 1994, p. 134).

Assim, existem disputas entre informações que transmitem um discurso da verdade sobre vários aspectos da nossa vida. Estão materializadas nas instituições, divulgam e contribuem para a internalização de visões de mundo, pois estão providas de ideologias, além de serem elementos de "[...] continuidade do passado, reelaborado e reinterpretado à luz do tempo presente que nos organiza e constitui o princípio da nossa identidade." (MARTELETO, 1994, p.132). As práticas informacionais seriam parte da construção da cultura, "[...] admitindo-se que existem tantas formas de lidar com o mundo, quantas existem de experiências e de condições de vida." (MARTELETO, 1994, p. 133).

Araújo (2017) num artigo cujo título questiona "O que são 'práticas informacionais'?" inicia retomando Pierre Bourdieu e sua abordagem sociológica que considera que as pessoas vivem sob um "sistema de relações objetivas" que se interioriza na formação dos indivíduos que acabam agindo ou tendo disposições para agir de acordo com as definições desse sistema.

É nesse sentido que estudar as práticas informacionais constitui-se num movimento constante de capturar as disposições sociais, coletivas (os significados socialmente partilhados do que é informação, de quais são as fontes ou recursos adequados) e também as elaborações e perspectivas individuais de como se relacionar com a informação (a aceitação ou não das regras sociais, a negociação das necessidades de informação, o reconhecimento de uma ou outra fonte de informação como legítima, correta, atual), num permanente tensionamento entre as duas dimensões, percebendo como uma constitui a outra e vice-versa. (ARAÚJO, 2017, p. 220221).

Sirihal Duarte (2017) abordou, em seu trabalho apresentado no Encontro Nacional de Pesquisa em Ciência da Informação (ENANCIB), o uso do conceito de práticas informacionais em pesquisas de estudos de usuários e sua abordagem no ensino na pós-graduação. A autora fez levantamento de investigações que foram orientadas por docentes do grupo de pesquisa Estudos em Práticas Informacionais e Cultura (EPIC) da Universidade Federal de Minas 
Gerais (UFMG), cujo objetivo é olhar para as "[...] interações do sujeito com o contexto numa perspectiva dialógica, em que tanto o contexto interfere nas práticas do sujeito quanto este altera o próprio contexto em que se insere." (SIRIHAL DUARTE, 2017, p. 70). Estudos em profundidade, realizados com metodologias qualitativas, muitas vezes, com uso do aporte etnográfico.

\section{Quadro 2 - Histórico das pesquisas vinculadas ao Grupo EPIC/UFMG}

\begin{tabular}{|c|c|c|c|}
\hline Temática & Metodologia & $\begin{array}{c}\text { Papel social do sujeito } \\
\text { informacional }\end{array}$ & Aporte teórico \\
\hline $\begin{array}{l}\text { Descreve e analisa as práticas infor- } \\
\text { macionais das profissionais do sexo } \\
\text { da zona boêmia de Belo Horizonte. } \\
\text { (SILVA, 2008). }\end{array}$ & $\begin{array}{l}\text { Coleta de dados: rela- } \\
\text { tos, entrevistas, com } \\
\text { gravação em áudio. } \\
\text { Análise de dados: aná- } \\
\text { lise de conteúdo. }\end{array}$ & Profissionais do sexo. & $\begin{array}{l}\text { Práticas Informacio- } \\
\text { nais; paradigma social } \\
\text { da Ciência da Informa- } \\
\text { ção. }\end{array}$ \\
\hline $\begin{array}{l}\text { Busca compreender as práticas in- } \\
\text { formacionais de ouvintes assíduos de } \\
\text { rádio. (PESSOA, 2010). }\end{array}$ & $\begin{array}{l}\text { Coleta de dados: rela- } \\
\text { tos, entrevistas, com } \\
\text { gravação em áudio. } \\
\text { Análise de dados: aná- } \\
\text { lise de conteúdo. }\end{array}$ & $\begin{array}{l}\text { Ouvintes assíduos de } \\
\text { rádio. }\end{array}$ & $\begin{array}{l}\text { Descrição densa de } \\
\text { Geertz; } \\
\text { Dimensão emocional } \\
\text { de Maffesoli. }\end{array}$ \\
\hline $\begin{array}{l}\text { Busca compreender como os idosos } \\
\text { percebem, descrevem e atribuem } \\
\text { significado à experiência da inclusão } \\
\text { digital e seus efeitos na vida diária, } \\
\text { perpassando pelo campo da sociabi- } \\
\text { lidade e do comportamento informa- } \\
\text { cional. (GANDRA, 2012). }\end{array}$ & $\begin{array}{l}\text { Coleta de dados: en- } \\
\text { trevistas semiestrutu- } \\
\text { radas em profundida- } \\
\text { de, com gravação em } \\
\text { áudio. Análise de da- } \\
\text { dos: análise de conteú- } \\
\text { do. }\end{array}$ & $\begin{array}{l}\text { Idosos que tenham se } \\
\text { incluído digitalmente. }\end{array}$ & $\begin{array}{l}\text { Abordagem social dos } \\
\text { estudos de usuários; } \\
\text { Fenomenologia social } \\
\text { de Alfred Schutz. }\end{array}$ \\
\hline $\begin{array}{l}\text { Investiga a maneira dos professores } \\
\text { produzirem, disseminarem e apropri- } \\
\text { arem de informações para a sua } \\
\text { organização político-sindical, consi- } \\
\text { derando as suas posições como sindi- } \\
\text { calizado, não sindicalizado, militante } \\
\text { de organização política e dirigente } \\
\text { sindical. (PINTO, 2012). }\end{array}$ & $\begin{array}{l}\text { Coleta de dados: en- } \\
\text { trevistas semiestrutu- } \\
\text { radas. }\end{array}$ & $\begin{array}{l}\text { Professores da Rede } \\
\text { Municipal de Ensino de } \\
\text { Belo } \quad \text { Horizonte } \\
\text { (RMEBH)/MG. }\end{array}$ & $\begin{array}{lr}\text { Práticas } & \text { informacio- } \\
\text { nais; } & \\
\text { Aporte } & \text { teórico- } \\
\text { metodológico de Pierre } \\
\text { Bourdieu. }\end{array}$ \\
\hline $\begin{array}{l}\text { Investiga como pessoas com cegueira } \\
\text { congênita e adquirida interagem com } \\
\text { a Web e como percebem sua } \\
\text { (in)acessibilidade, buscando identifi- } \\
\text { car as carências e contribuições das } \\
\text { Diretrizes de Acessibilidade para o } \\
\text { Conteúdo da Web WCAG } 2.0 \text { para a } \\
\text { construção de websites mais ade- } \\
\text { quados a esse perfil de usuários. } \\
\text { (ROCHA, 2013). }\end{array}$ & $\begin{array}{l}\text { Coleta de dados: en- } \\
\text { trevistas semiestrutu- } \\
\text { radas envolvendo } \\
\text { ensaios de interação, } \\
\text { com gravação de áudio } \\
\text { e salvamento das telas. } \\
\text { Análise de dados: aná- } \\
\text { lise de conteúdo. }\end{array}$ & $\begin{array}{l}\text { Pessoas cegas (defini- } \\
\text { ção pedagógica: aque- } \\
\text { las que, mesmo com } \\
\text { baixa visão, necessitam } \\
\text { de instrução em braille } \\
\text { ou do auxílio de leito- } \\
\text { res de tela). }\end{array}$ & $\begin{array}{l}\text { Abordagem social dos } \\
\text { estudos de usuários; } \\
\text { Cognição Situada. }\end{array}$ \\
\hline $\begin{array}{l}\text { Busca indícios de como a subjetivida- } \\
\text { de interfere no processo decisório, } \\
\text { ou como os aspectos subjetivos se } \\
\text { integram às competências individuais } \\
\text { para influenciar esse processo. Inves- } \\
\text { tigou o processo decisório de biblio- } \\
\text { tecários durante a atividade de inde- } \\
\text { xação em bibliotecas universitárias. } \\
\text { (ARAUJO, 2013). }\end{array}$ & $\begin{array}{l}\text { Coleta de dados: en- } \\
\text { trevista, análise de } \\
\text { tarefas, protocolo } \\
\text { verbal, aplicação do } \\
\text { AT-9. Análise de dados: } \\
\text { análise de conteúdo, } \\
\text { análise do AT-9, análise } \\
\text { de símbolos. }\end{array}$ & $\begin{array}{l}\text { Bibliotecários universi- } \\
\text { tários. }\end{array}$ & $\begin{array}{l}\text { Abordagem clínica da } \\
\text { informação; } \\
\text { Teste dos } 9 \text { arquétipos. }\end{array}$ \\
\hline
\end{tabular}

Fonte: Sirihal Duarte (2017). 
É também nesse grupo que se tem tentado ampliar e fortalecer o conceito de práticas informacionais. Apesar dos trabalhos usarem o conceito de práticas informacionais ou da abordagem social dos estudos de usuários, há consideráveis diferenças na abordagem teórico-metodológica. Entretanto, todos partem do princípio da pesquisa qualitativa, da consideração do sujeito e sua relação com o contexto local ou com uma perspectiva histórico-social mais ampla.

Entre os trabalhos apresentados no Quadro 2, a pesquisa de Pinto (2012) buscou ampliar o conceito de práticas informacionais relacionando-o com a praxiologia de Pierre Bourdieu (BOURDIEU,1983; ORTIZ, 1983), mas com uma abordagem diferenciada da usada pelo estudo já citado de Savolainen (1995). A autora considerou as práticas informacionais como necessidades, ações de busca, uso, produção e disseminação de informações num tempo e espaço determinados não somente pelas ideias dos sujeitos, mas pela historicidade, a posição de classe e os conflitos existentes. Assim, ao analisar as práticas informacionais dos professores da RMEBH, partiu da apresentação da situação do trabalho docente na contemporaneidade por entender que os professores atuam nessa realidade e também são construídos por relações estabelecidas nessa conjuntura.

Fez-se necessária a apresentação da conjuntura do movimento sindical docente a nível nacional e local que também conformava as práticas informacionais em torno da organização político-sindical dos docentes em busca da resolução das demandas relacionadas às condições de trabalho, da saúde e da remuneração. Localizaram-se também historicamente a situação do trabalho, a carreira e a remuneração dos professores para ampliar o entendimento sobre suas demandas e as maneiras como se organizam e se comunicam no local de trabalho e em outros espaços, apontando as diferenças de acesso às informações entre professores sindicalizados, não sindicalizados e os dirigentes sindicais. (PINTO, 2012).

A percepção da autora não se limitava ao contexto de realização das práticas, mas na construção histórica das condições de trabalho e organização política-sindical dos docentes que pode variar de uma cidade para outra, de um país para outro. Além disso, ao analisar os relatos dos sujeitos entrevistados a partir da teoria da formação do Habitus, nos atentamos para a formação deles ao longo da vida e as influências que os levaram a estabelecer relações com o movimento associativo docente e como recebiam, produziam e disseminavam informações nesse sentido no seu cotidiano. Não nos preocupamos em elaborar um modelo que pudesse ser replicado, ao entendermos que as práticas informacionais serão únicas, determinadas social e historicamente pelas relações entre os indivíduos e a organização das classes sociais que é dinâmica e conflituosa.

Entendemos que o conceito de práticas informacionais foi um avanço em relação ao conceito de comportamento informacional, por considerar as influências contextuais, sociais nos estudos dos fenômenos informacionais. Vários autores buscaram nas Ciências Sociais arcabouços teórico-metodológicos para uma melhor orientação das pesquisas empíricas. Se por um lado há o problema da ausência de uma melhor teorização do conceito de práticas informacionais, por outro lado, as pesquisas apontam diversas maneiras de se analisar os fenômenos informacionais, fortalecendo o debate em torno dessa questão.

\section{CONSIDERAÇÕES FINAIS}

As diferentes abordagens dos estudos de usuários demonstram importância e a complexidade dessa temática por se tratar de fenômenos dinâmicos que surgiram na nossa 
convivência em comunidade. Houve um avanço teórico-metodológico importante nos estudos ao passarem a considerar as determinações sociais para o entendimento da relação humana com os fenômenos informacionais. Entretanto, necessitamos avançar na melhor conceituação de comportamento informacional e práticas informacionais que, atualmente, se apresentam como conceitos guarda-chuvas como definido por Savolainen (2007).

Entendemos por práticas informacionais os processos que envolvem as necessidades, a busca, o uso, a produção e a disseminação de informações pelos indivíduos em todos os momentos da sua vivência dada em determinadas condições históricas e sociais, que variam no espaço e no tempo. Não é um conceito tácito ou natural. Dessa maneira, sugerimos a ampliação dessa abordagem a partir da historicidade que envolve a construção e atuação dos sujeitos que já nascem e vivem em comunidade.

Conforme apontaram Marx e Engels (2007, p. 64), ao criticarem os filósofos alemães do princípio do Século XIX, "os indivíduos partiram sempre de si mesmos no interior de condições e relações históricas dadas, e não do indivíduo 'puro' nos sentidos dos ideólogos". Assim, ao abordarmos a relação de determinado grupo social com a informação, precisamos resgatar a historicidade local e nacional onde vive o grupo, considerando categorias como, por exemplo, gênero, classe social, etnia, não somente como meros atributos para a caracterização dos sujeitos. Essas categorias vistas do ponto de vista histórico-social têm muito a nos dizer sobre a conformação das práticas informacionais.

Acreditamos ser necessário escapar da necessidade de se elaborar modelos sobre comportamentos informacionais, numa tentativa de se buscar a generalização de atitudes dos indivíduos com relação aos fenômenos informacionais. Como apontou Case (2002) cabe ao pesquisador a criatividade e o esforço de aplicar a melhor abordagem teóricometodológica conforme a situação e o grupo social pesquisado. Entretanto, não podemos deixar escapar a essência social e histórica da nossa existência, de como a vida em comunidade conforma nosso entendimento de mundo e nossas ações ao mesmo tempo em que também refletimos e atuamos sobre o mundo buscando, usando, criando, recriando e disseminando informações sobre absolutamente tudo o que nos rodeia.

\section{REFERÊNCIAS}

ARAÚJO, C. A. A. Abordagem interacionista de estudos de usuários da informação. PontodeAcesso, v. 4, n. 2, p. 2-32, set. 2010. Disponível em:

https://portalseer.ufba.br/index.php/revistaici/article/viewFile/3856/3403. Acesso em: 05 set. 2019.

ARAUJO, C. A. A. Estudos de usuários: pluralidade teórica, diversidade de objetos. In: ENCONTRO DA ASSOCIAÇÃO NACIONAL DE PESQUISA E PÓS-GRADUAÇÃO EM CIÊNCIA DA INFORMAÇÃO, 9., 2008, São Paulo. Anais eletrônicos [...]. São Paulo: Associação Nacional de Pesquisa e Pós-Graduação em Ciência da Informação, 2008.

ARAÚJO, C. A. A. O que são "práticas informacionais"? Informação em pauta, Fortaleza,v. 2, n. esp., p. 217-236, out. 2017. Disponível em:

http://periodicos.ufc.br/informacaoempauta/article/view/20655/31068. Acesso em: 05 set. 2019. 
ARAUJO, E. P. O. Tomada de decisão organizacional e subjetividade: análise das dimensões simbólico-afetivas no uso da informação em processos decisórios. 2013. 165f. Dissertação. (Mestrado em Ciência da Informação) - Universidade Federal de Minas Gerais, Belo Horizonte, 2013.

BAPTISTA, S. G.; CUNHA, M. B. Estudo de usuários: visão global dos métodos de coleta de dados. Perspectivas em Ciência da Informação, Belo Horizonte, v. 12, n. 2, p. 168-184, maio/ago. 2007. Disponível em:

http://portaldeperiodicos.eci.ufmg.br/index.php/pci/article/view/48/89. Acesso em: 20 nov. 2019.

BELKIN, N. J. Anomalous states $\mathrm{f}$ knowledge as a basis for information retrieval. The Canadian Journal of Information Science, v. 5, p. 133-143, 1980.

BOURDIEU, P. Esboço de uma teoria da prática. In: ORTIZ, R. (Org.). Pierre Bourdieu: Sociologia. São Paulo: Ática, 1983. p.46-81.

BURNHAM, T. F. Análise contrastiva: memória da construção de uma metodologia para investigar a tradução de conhecimento científico em conhecimento público. DataGramaZero, Rio de Janeiro, v. 3, n. 3, p. 1-16 2002.

CALVA GONZÁLEZ, J. J. Las necesidades de información: fundamentos teóricos y métodos. México: UNAM, 2004.

CASE, D. O. Looking for information: a survey of research on information seeking, needs, and behavior. San Diego: Academic Press, 2002.

CHATMAN, E. A theory of life in the round. Journal of the American Society for Information Science, v. 50, n.3, p.207-217, 1999.

CHOO, C. W. Como ficamos sabendo - um modelo de uso da informação. In: CHOO , C. W. A organização do conhecimento: como as organizações usam a informação para criar significados, construir conhecimento e tomar decisões. São Paulo: Senac, 2003. Cap.2, p. 63 - 120.

CLANCEY, W. J. Situated cognition: on human knowledge and computer representations. Cambridge: Cambridge University Press, 1997.

COSTA, L. F.; RAMALHO, F. A. A usabilidade nos estudos de uso da informação: em cena, usuários e sistemas interativos de informação. Perspectivas em Ciência da Informação, Belo Horizonte, v. 15, n. 1, p. 92-117, jan./abr. 2010a. Disponível em:

http://portaldeperiodicos.eci.ufmg.br/index.php/pci/article/view/887/713. Acesso em: : 05 set. 2019.

COSTA, L. F.; RAMALHO, F. A. Comportamento infocomunicacional: perspectivas sobre definição, práticas e modelos de estudos. Revista Brasileira de Biblioteconomia e Documentação, São Paulo, v. 15, n. 2, p. 133-158, maio 2019. Disponível em:

https://rbbd.febab.org.br/rbbd/article/view/1162. Acesso em: 05 set. 2019. 
COSTA, L. F.; RAMALHO, F. A. Novas perspectivas dos estudos de satisfação de usuários. Encontros Bibli: revista de Biblioteconomia e Ciência da Informação, Florianópolis, v. 15, n. 30, p.57-73, 2010b. Disponível em: https://periodicos.ufsc.br/index.php/eb/article/view/15182924.2010v15n30p57/19530. Acesso em: 05 set. 2019.

COSTA, L. F.; SILVA, A. C. P.; RAMALHO, F. A. R. (Re)visitando os estudos de usuário: entre a "tradição" e o "alternativo". Datagramazero, v. 10, n. 4, jul./ago. 2009.

COURTRIGHT. C. Context in Information Behavior Research. Annual Review of Information Science and Tecnology, v. 41, p. 273-306, 2007.

DERVIN, B. Sense-making theory and practice: an overview of user interests in knowledge seeking and use. Journal of Knowledge Management, v. 2, n. 2, dec. 1998.

ELLIS, D. A behavioral approach to information retrieval system design. Journal of Documentation, London, v. 45, n. 3, p. 171-212, sep. 1989.

ELLIS, D.; COX, D.; HALL, K. A comparasionof the informacion seekingof researchers in the physical and social science. Journal of Documentation, London, v. 49, n. 4, p. 356-369, 1993.

FERREIRA, S. M. S. P. Novos paradigmas da informação e novas percepções do usuário. Ciência da Informação, Brasília, v. 25, n. 2, p. 217-223, maio/ago. 1996. Disponível em: http://revista.ibict.br/ciinf/article/view/660/664. Acesso em: 20 nov. 2019.

FIGUEIREDO, N. Estudos de uso e usuários da informação. Brasília: IBICT, 1994.

GANDRA, T. K. Inclusão digital na terceira idade: um estudo de usuários sob a perspectiva fenomenológica. 2012. 137f. Dissertação. (Mestrado em Ciência da Informação) - Universidade Federal de Minas Gerais, Belo Horizonte, 2012.

GASQUE, K. C. G. D.; COSTA, S. M. S. Evolução teórico metodológica dos estudos de comportamento informacional de usuários. Ciência da Informação, Brasília, v.39, n.1, p. 21-32, jan./abr. 2010. Disponível em: http://revista.ibict.br/ciinf/article/view/1285/1463. Acesso em: 20 nov. 2019.

INSTITUTO BRASILEIRO DE GEOGRAFIA E ESTATÍSTICA - IBGE. Censo do ano de 2010. Disponível em: http://censo2010.ibge.gov.br/. Acesso em: 30 ago. 2019.

KUHLTHAU, C. The role of experience in the information search process of an early career information worker: perceptions of uncertainty, complexity, construction and sources. Journal of the American Society of Information Science. v. 50, n. 5, p. 399- 412, 1999.

MAFRA PEREIRA, F. C. Modelo integrativo - comportamento informacional para decisões estratégicas: estudos de caso em MPES mineiras. In: ENCONTRO NACIONAL DE PESQUISA EM CIÊNCIA DA INFORMAÇÃO, 14., 2013, Florianópolis. Anais [...] Florianópolis: Associação Nacional de Pesquisa e Pós-Graduação em Ciência da Informação, 2013. 
MARCONI, M. A; LAKATOS, E. M. Técnicas de pesquisa. São Paulo: Atlas. 2006.

MARTELETO, R. M. Cultura da modernidade: discussões e práticas informacionais. Revista Escola de Biblioteconomia da UFMG, Belo Horizonte, v. 23, n. 2, p. 115-137, jul./dez. 1994.

MARTIN, L. Community analysis for the library. In: CARNOVSKY, L.; MARTIN, L. (Eds.). The Library in the Community. Chicago: University of Chicago Press, 1944.

MARX, K.; ENGELS, F. A ideologia alemã. Tradução de Rubens Enderle, Nélio Schneider, Luciano Cavini Martorano. São Paulo: Boitempo, 2007.

MCKENZIE, P. J. A modelo of infomation practices in accounts of everyday-life information seeking. Journal of Documentation, Bingley, v. 59, n. 1, p. 19-40, 2003.

MCMILLEN, W. The Community Survey. In: CARNOVSKY, L.; MARTIN, L. (Eds.). The Library in the Community. Chicago: University of Chicago Press, 1944.

MIRANDA, M. K. O acesso à informação no paradigma pós-custodial: da aplicação da intencionalidade para a findability. 2010. 353f. Tese (Doutorado em Informação e Comunicação em Plataformas Digitais) - Faculdade de Letras da Universidade do Porto, Porto, Portugal, 2010.

ORTIZ, R. (Org.). Pierre Bourdieu: Sociologia. São Paulo: Ática, 1983.

PAULA, C. P. A. A investigação do comportamento de busca informacional e do processo de tomada de decisão dos líderes nas organizações: introduzindo a Abordagem Clínica da Informação como proposta metodológica. Perspectivas em Gestão \& Conhecimento, João Pessoa, v. 3, n. esp., p. 30-44, out. 2013. Disponível em: http://www.brapci.inf.br/index.php/res/download/57102. Acesso em 05 set. 2019.

PESSOA, M. T. A relação entre ouvintes assíduos e o rádio: um estudo de usuários da informação a partir de uma perspectiva compreensiva. 2010. 95f. Dissertação. (Mestrado em Ciência da Informação) - Universidade Federal de Minas Gerais, Belo Horizonte, 2010.

PINTO, F. V. M. Práticas informacionais na organização político-sindical dos professores da rede municipal de Belo Horizonte. 2012. 150f. Dissertação (Mestrado em Ciência da Informação) - Universidade Federal de Minas Gerais, Escola de Ciência da Informação, Belo Horizonte, 2012.

ROCHA, J. A. P. (In)acessibilidade na web para pessoas com deficiência visual: um estudo de usuários à luz da Cognição situada. 2013. 160f. Dissertação. (Mestrado em Ciência da Informação) - Universidade Federal de Minas Gerais, Belo Horizonte, 2013.

SAVOLAINEN, R. Everyday life information seeking: approaching information seeking in the context of "way of life". Library \& Information Science Research, Amsterdam, v. 17, n. 3, p. 259-294, 1995. 
SAVOLAINEN, R. Information Behavior and Information Practice: Reviewing the "Umbrella Concepts" of Information-Seeking Studies. Library Quarterly, Chicago, v. 77 n. 2, p. 109-132. 2007.

SILVA, L. L.; SILVA, A. M. Comportamento infocomunicacional em contextos de redes sociais online: proposta de investigação. In: INTERNATIONAL CONFERENCE ON INFORMATION SYSTEMS AND TECHNOLOGY MANAGEMENT, 9., 2012, São Paulo. Proceedings [...] São Paulo: Universidade de São Paulo, 2012.

SILVA, R. A. As práticas informacionais das Profissionais do Sexo da zona boêmia de Belo Horizonte. 2008. Dissertação (Mestrado em Ciência da Informação) - Universidade Federal de Minas Gerais, Escola de Ciência da Informação, Belo Horizonte, 2008.

SIRIHAL DUARTE, A. B. Práticas informacionais: ensino e pesquisa. In: ENCONTRO NACIONAL DE PESQUISA EM CIÊNCIA DA INFORMAÇÃO, 28., 2017, Marília. Anais [...] Marília: Associação Nacional de Pesquisa e Pós-Graduação em Ciência da Informação, 2017.

TAYLOR, R. S. Value-added processes in information systems. New Jersey: Ablex, 1986.

THE WORD BANK. Quase metade do mundo vive com menos de USD $\$ 5.50$ por dia. Comunicado à imprensa, 17 out. 2018. Disponível em: https://www.worldbank.org/pt/news/pressrelease/2018/10/17/nearly-half-the-world-lives-on-less-than-550-a-day-brazilianportuguese. Acesso em: 02 set. 2019.

WIGHT, E. A. Methods and Techniques of Library Surveys. In: WILSON, L. R. (Ed.). Library Trends. Chicago, 1937. p. 346.

WILSON, T. D. Human Information Behavior. Information Science Research, v. 3, n. 2, p. 49$53,2000$.

WILSON, T. D. On user studies and information needs. Journal of Documentation, v. 37, n. 1, p. 3-15, 1981.

YEOMAN, A. Applying McKenzie's model of information practices in everyday life information seeking in the context of the menopause transition. Information Research, v. 15, n. 4, 2010. Disponível em: http://InformationR.net/ir/154/paper444.html. Acesso em: 12 jul. 2018. 